\title{
Efeito do ciclo de queima sobre as propriedades tecnológicas de uma massa cerâmica vermelha para revestimento poroso
}

\author{
(Effect of firing cycle on the technological \\ properties of a red wall tile paste) \\ M. F. Pinto, S. J. G. Sousa, J. N. F. Holanda \\ Grupo de Materiais Cerâmicos, LAMAV \\ Universidade Estadual do Norte Fluminense \\ Av. Alberto Lamego 2000, Campos dos Goytacazes, RJ 28013-602 \\ sidnei@uenf.br
}

\begin{abstract}
Resumo
No presente trabalho foi feita uma análise comparativa das propriedades tecnológicas de uma massa cerâmica vermelha para revestimento poroso queimada em dois distintos ciclos de queima, sendo um ciclo de queima lento tradicional e um ciclo de queima rápido. Os corpos cerâmicos foram queimados entre 1080 e $1160{ }^{\circ} \mathrm{C}$. As seguintes propriedades tecnológicas foram determinadas: retração linear, absorção de água, massa específica aparente e tensão de ruptura à flexão. Análise microestrutural foi realizada por meio de difração de raios X e microscopia eletrônica de varredura. Os resultados experimentais mostraram claramente que o emprego de um ciclo de queima lento resultou em melhores propriedades dos corpos cerâmicos sinterizados.
\end{abstract}

Palavras-chave: revestimento poroso, ciclo de queima, propriedades.

\begin{abstract}
In this work was done a comparative analysis of the technological properties of a red wall tile ceramic paste fired in two different firing cycles, being a traditional slow-firing cycle and a fast-firing cycle. The ceramic pieces were fired between 1080 and $1160{ }^{\circ} \mathrm{C}$. The following technological properties were determined: linear shrinkage, water absorption, apparent density and flexural strength. Microstructural analysis was performed using X-ray diffraction and scanning electron microscopy. The experimental results indicated clearly that the use of a slow-firing cycle resulted in enhanced properties of the red wall tiles.
\end{abstract}

Keywords: wall tile, firing cycle, properties.

\section{INTRODUÇÃO}

A queima é a etapa principal da rota tecnológica de fabricação de um produto cerâmico. É nesta etapa que ocorre a consolidação do formato da peça definido na operação de conformação do pó [1]. Esta etapa do processo de fabricação vem passando nos últimos anos, no setor de revestimentos cerâmicos, por constantes modificações com destaque para a redução cada vez mais significativa dos ciclos de queima levando a um incremento na produtividade [2, 3]. A introdução de ciclos de queima rápidos constitui-se numa das mais importantes inovações do setor de revestimentos cerâmicos. O comportamento das diferentes matérias-primas frente à ação do calor irá definir, em muitos casos, a tipologia de produto a ser fabricado, suas características técnicas e as variáveis de queima empregadas, isto é, temperatura máxima de queima e duração do ciclo de queima.
O monitoramento das propriedades tecnológicas é de fundamental importância para que se conheça o intervalo de queima em que as dimensões e a porosidade da peça cerâmica não variem excessivamente [4]. O ciclo de queima deverá ser ajustado de modo que a taxa de aquecimento seja menor nos intervalos de temperatura em que a variação dimensional é maior. Se por um lado a temperatura de queima fornece a energia para que as reações possam ocorrer, por outro, o tempo de queima irá permitir que essas reações possam atingir o equilíbrio estabelecido pela termodinâmica. Além disso, é a combinação dos fatores temperatura e tempo de queima (ciclo térmico) que estabelece o grau de transformações sofridas por um compacto durante a queima [5]. Portanto, é importante que se conheça a sensibilidade de uma massa cerâmica a variações no ciclo de queima. Além disso, existem poucos trabalhos que comparam as propriedades tecnológicas de produtos cerâmicos queimados 
usando ciclos de queima tradicional e rápido [3].

O presente trabalho teve por objetivo analisar, comparativamente, as propriedades tecnológicas de uma massa cerâmica vermelha para revestimento poroso (BIII) queimada em dois distintos ciclos de queima, sendo um ciclo de queima lento tradicional e um ciclo de queima rápido.

\section{MATERIAIS E MÉTODOS}

Uma massa cerâmica para revestimento poroso base vermelha foi formulada [5] e sua composição é dada por: $70 \%$ em peso de argila, $15 \%$ em peso de calcário e $15 \%$ em peso de quartzo. Foram utilizadas como matérias-primas uma argila do município de Campos dos Goytacazes-RJ, um calcário do município de Italva-RJ e um quartzo comercial.

A argila e o calcário foram moídos a seco em moinho de bolas (Gardelin, modelo 1A MB5) até não retenção na peneira de 200 mesh (75 $\mu \mathrm{m}$ ABNT). O quartzo, fornecido na granulometria inferior a 200 mesh, foi utilizado conforme recebido. A massa cerâmica foi então submetida a um processo de microgranulação realizado num microgranulador intensivo (EIRICH, modelo R02), com umidade da ordem de $14 \%$. Em seguida, foi feito o controle da umidade para cerca de $7 \%$ da massa microgranulada. Os grãos grossos (> $2 \mathrm{~mm}$ ) foram eliminados do processo.

Os corpos cerâmicos obtidos por prensagem uniaxial sob 35 MPa numa matriz retangular (115 x 25,4 x 7,5 mm $)$ foram secos em estufa $\left(110{ }^{\circ} \mathrm{C}\right.$ por $\left.24 \mathrm{~h}\right)$. As amostras compactadas apresentaram a mesma massa específica a verde. Isto é necessário no sentido de eliminar ou minimizar diferenças na porosidade das peças cerâmicas, que podem significativamente influenciar as propriedades tecnológicas e a microestrutura a serem investigados. A queima foi feita em temperaturas de 1080 até $1160{ }^{\circ} \mathrm{C}$ utilizando-se dois ciclos de queima distintos, sendo um ciclo lento $(\cong 24 \mathrm{~h})$ em forno elétrico de laboratório (BRASIMET, modelo $\mathrm{K}$ $\left.150-1300{ }^{\circ} \mathrm{C}\right)$ e um ciclo rápido ( $\cong 1 \mathrm{~h}$ ) em forno de queima rápida (MAITEC, modelo FSQC - 1300/3).

Após a queima, as seguintes propriedades tecnológicas dos corpos cerâmicos foram determinadas: retração linear [6] absorção de água [7], massa específica aparente [7] e tensão de ruptura à flexão [8] (ensaio de carregamento em três pontos).

As peças cerâmicas foram submetidas a ensaios de difração de raios X em um difratômetro, marca Seifert, modelo URD-65, usando radiação $\mathrm{Cu}-\mathrm{K} \alpha$. A microestrutura das amostras sinterizadas foi observada usando um microscópio eletrônico de varredura (DSM 962, Zeiss), com voltagem de aceleração da ordem de $15 \mathrm{kV}$.

\section{RESULTADOS E DISCUSSÃO}

Os espectros de difração de raios X da massa cerâmica vermelha para revestimento poroso são mostrados na Fig. 1.
As fases cristalinas principais identificadas foram: caulinita $\left(\mathrm{Al}_{2} \mathrm{O}_{3} \cdot 2 \mathrm{SiO}_{2} \cdot 2 \mathrm{H}_{2} \mathrm{O}\right)$, calcita $\left(\mathrm{CaCO}_{3}\right)$, quartzo $\left(\mathrm{SiO}_{2}\right)$, gibsita $\left(\mathrm{Al}_{2} \mathrm{O}_{3} \cdot 3 \mathrm{H}_{2} \mathrm{O}\right)$ e dolomita $\left(\mathrm{CaMgCO}_{3}\right)$. Além disso, foram identificadas também as presenças de fases como ilita/mica, goetita e feldspato potássico. Nota-se que quando a temperatura é elevada até $1140^{\circ} \mathrm{C}$ ocorreram uma série de transformações de fases, que dependem da natureza química e mineralógica das matérias-primas utilizadas. Verifica-se que além do quartzo remanescente, foram detectados picos característicos da cristalização de fases como guelenita $\left(\mathrm{Ca}_{2} \mathrm{Al}_{2} \mathrm{SiO}_{7}\right)$ e anortita $\left(\mathrm{CaAl}_{2} \mathrm{Si}_{2} \mathrm{O}_{8}\right)$. Enquanto que mulita primária e hematita foram às fases minoritárias. Os resultados mostram, ainda, que as mesmas fases cristalinas foram identificadas para a massa cerâmica sinterizada em $1140{ }^{\circ} \mathrm{C}$, usando ambos os ciclos de queima tradicional e rápido. No entanto, observa-se que ocorreram ligeiras diferenças nas intensidades e largura dos picos de difração das fases guelenita, anortita, quartzo e hematita. Estas fases cristalinas apresentaram seus picos característicos mais intensos quando se utilizou um ciclo de queima lento. Isto pode estar relacionado à influência do ciclo de queima sobre as transformações de fases. Um ciclo de queima lento tende a favorecer a cinética e completeza das reações envolvidas.

Análise microestrutural por MEV da superfície de fratura das amostras sinterizadas usando um ciclo de queima tradicional é mostrada na Fig. 2a-b. Em $1100{ }^{\circ} \mathrm{C}$ (Fig. 2a) observase que a microestrutura é altamente porosa, resultante principalmente da decomposição do carbonato de cálcio para formar $\mathrm{CaO}$ com evolução de gás carbônico $\left(\mathrm{CO}_{2}\right)$. Quando a temperatura de patamar foi elevada até $1140^{\circ} \mathrm{C}$ (Fig. 2b), ocorreu a eliminação parcial de porosidade aberta na estrutura do material cerâmico. Pequenas zonas densas são formadas e provavelmente a matriz cerâmica é mais rica em fases cristalinas, como mostrado na Fig. 1. A

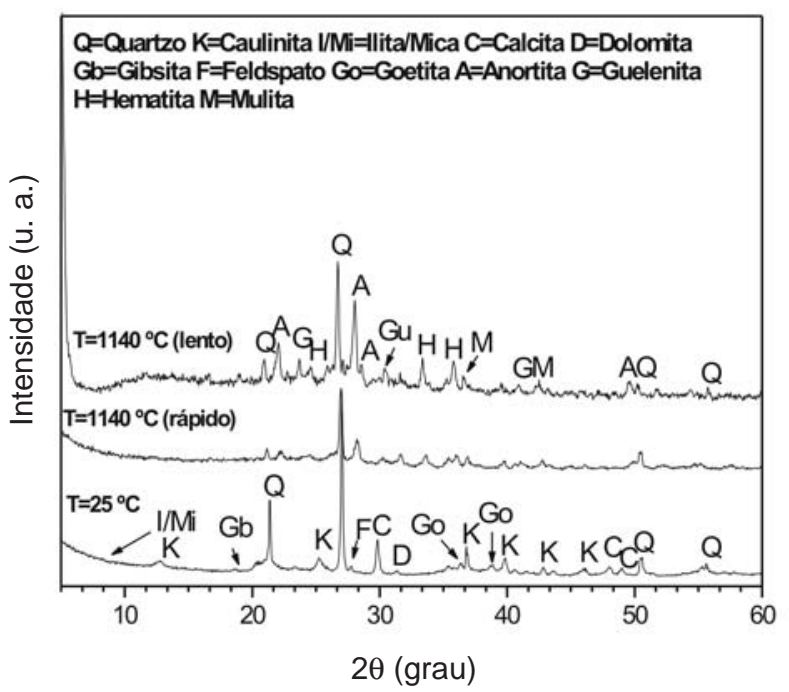

Figura 1: Difratogramas de raios $\mathrm{X}$ da massa cerâmica vermelha para revestimento poroso.

[Figure 1: X-ray diffraction patterns of the red wall tile paste.] 

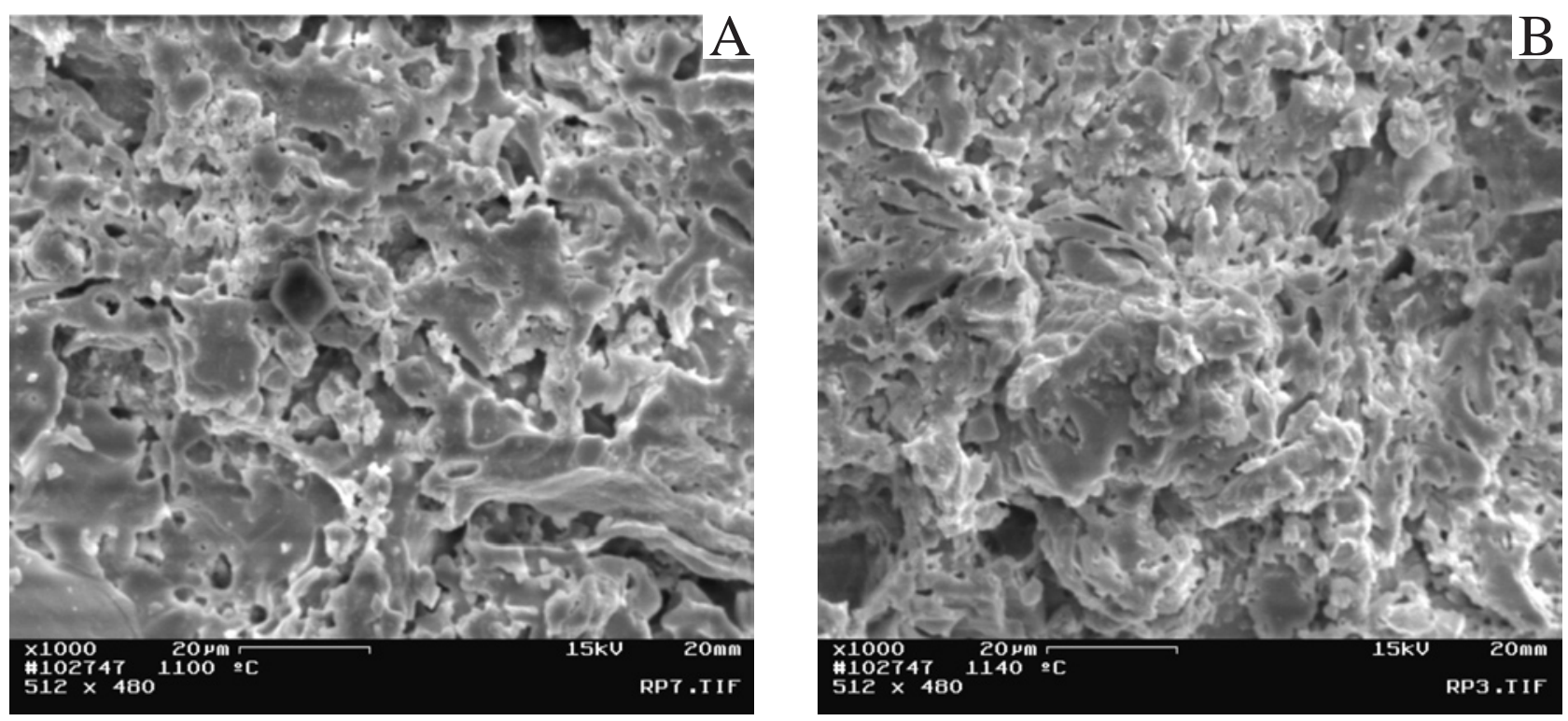

Figura 2: Micrografias obtidas por MEV das amostras sinterizadas usando um ciclo de queima tradicional: (a) $1100{ }^{\circ} \mathrm{C}$ e (b) $1140{ }^{\circ} \mathrm{C}$. [Figure 2: Micrographs obtained by SEM of the samples sintered using a traditional firing cycle: (a) $1100^{\circ} \mathrm{C}$ and (b) $1140{ }^{\circ} \mathrm{C}$.]
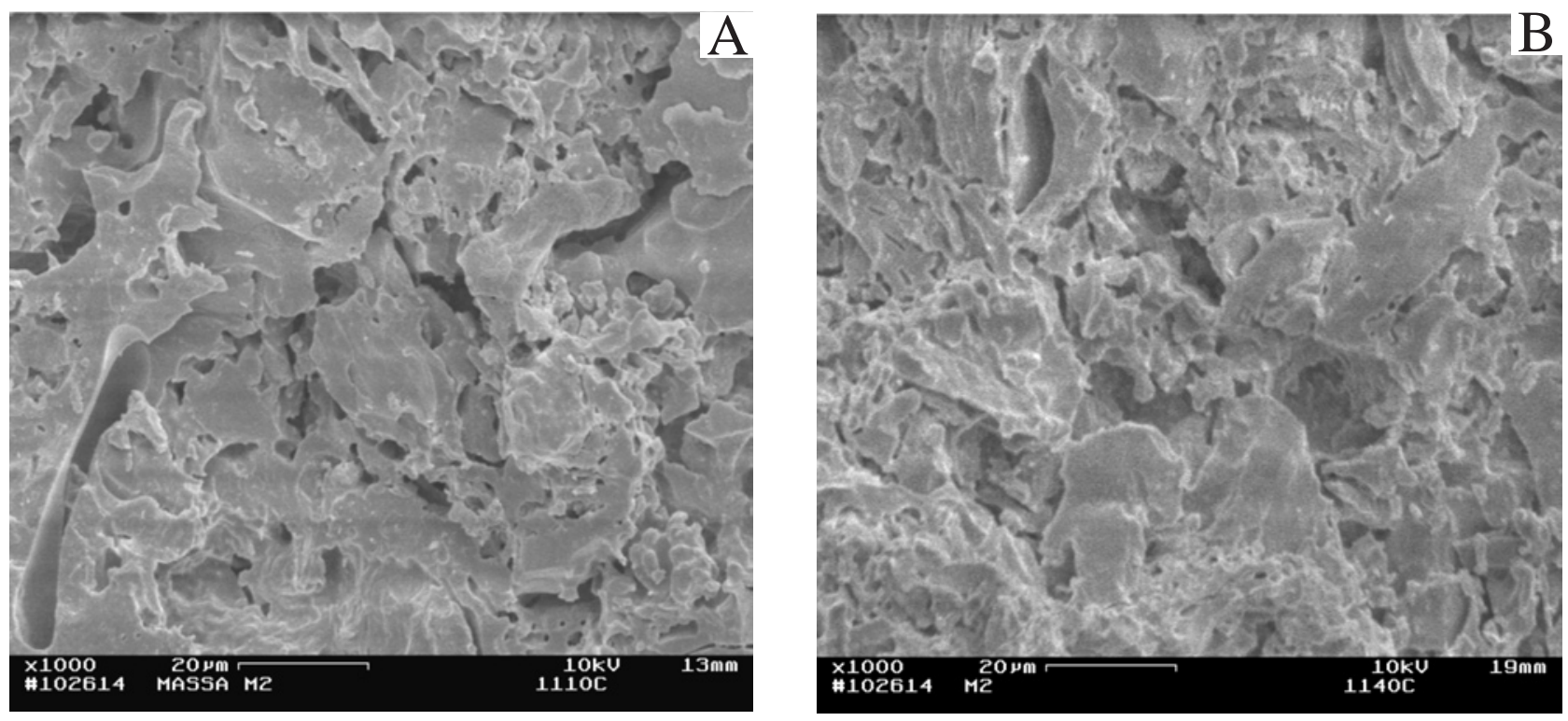

Figura 3: Micrografias obtidas por MEV das amostras sinterizadas usando um ciclo de queima rápido: (a) $1100{ }^{\circ} \mathrm{C}$ e (b) $1140{ }^{\circ} \mathrm{C}$. [Figure 3: Micrographs obtained by SEM of the samples sintered using a fast firing cycle: (a) $1100{ }^{\circ} \mathrm{C}$ and (b) $1140{ }^{\circ} \mathrm{C}$.]

estrutura mais homogênea com respeito a porosidade aberta contribuirá para maior resistência mecânica da peça cerâmica, particularmente a tensão de ruptura a flexão. A Fig. 3a-b mostra a microestrutura sinterizada para as amostras obtidas com um ciclo de queima rápido. Pode-se observar que a microestrutura sinterizada das amostras queimadas em um ciclo rápido é muito semelhante àquela sinterizada usando um ciclo de queima lento. Desta forma, não é possível identificar diferenças significativas na microestrutura do material cerâmico em relação ao ciclo de queima estudado.

Para acompanhar o processo de densificação da massa cerâmica e a tolerância a variações no ciclo de queima, foram construídos diagramas de gresificação, para ambos os ciclos, mostrados na Fig. 4. Nota-se que, tanto a absorção de água (AA), como a retração linear (RL) permanecem inalteradas dentro de certos intervalos de temperatura de queima. Estes intervalos são (1080 - $\left.1100{ }^{\circ} \mathrm{C}\right)$ para o ciclo de queima lento e $\left(1080-1140{ }^{\circ} \mathrm{C}\right)$ para o ciclo de queima rápido. Este comportamento está relacionado à formação de fases cristalinas (silicatos e aliminossilicatos de cálcio e/ou magnésio) alterando o curso das reações que ocorrem, sobretudo, a altas temperaturas. Estas fases interferem nas 


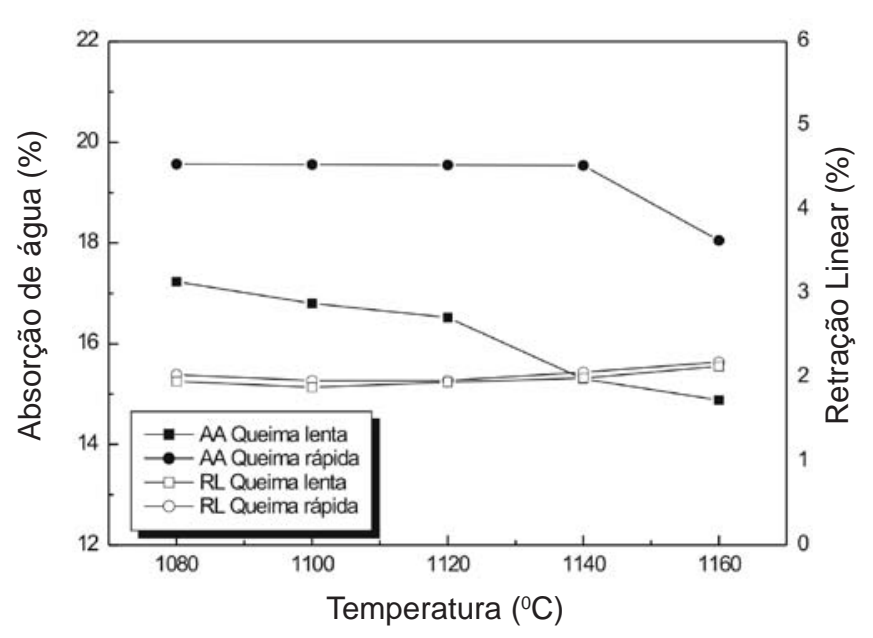

Figura 4: Curva de gresificação da massa cerâmica para revestimento poroso base vermelha.

[Figure 4: Gresification curve of the red wall tile paste.]

reações de formação de fase líquida. A formação destas fases cristalinas associadas à escassez de fases vítreas, nestes intervalos de temperatura, irá conferir aos corpos cerâmicos uma ampla margem de queima [9].

Comparando-se os resultados obtidos para os dois ciclos de queima estudados, observa-se que o parâmetro de retração linear permanece praticamente inalterado. No entanto, o parâmetro de absorção de água apresentou menores valores em toda faixa de temperatura quando foi utilizado o ciclo de queima lento. Este comportamento está relacionado ao maior tempo de exposição das peças na máxima temperatura de sinterização e, consequentemente, ao incremento da cinética das reações quando se utiliza o ciclo de queima lento.

Na Fig. 5 é mostrado o efeito do ciclo de queima e da temperatura de queima sobre a massa específica aparente dos corpos cerâmicos. Comparando-se os dois ciclos,

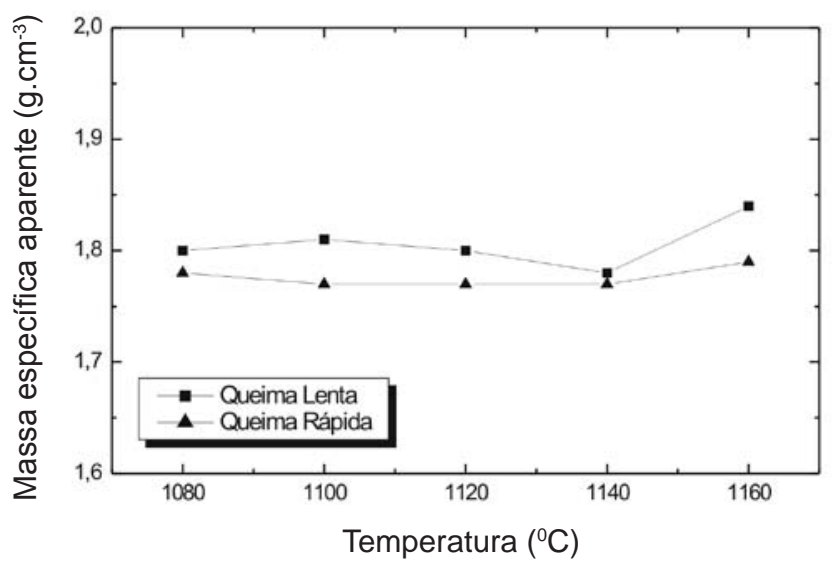

Figura 5: Massa específica aparente em função da temperatura de queima.

[Figure 5: Apparent Specific Mass as a function of firing temperature. observa-se que as peças queimadas no ciclo de queima lento apresentaram maiores valores de massa específica aparente. Este comportamento está relacionado ao maior tempo de queima do ciclo de queima tradicional, e corrobora os resultados de absorção de água. Um ciclo de queima mais longo provavelmente resultará na formação de uma maior quantidade de fases cristalinas de maior massa específica, com respeito à fase amorfa (metacaulinita) da qual elas são oriundas. Para os dois ciclos de queima, os valores desta propriedade se mantêm praticamente constantes à medida que se aumenta a temperatura de queima. Dessa forma, fica evidente o efeito da presença dos carbonatos na massa cerâmica em retardar o processo de densificação das peças cerâmicas.

A Fig. 6 mostra a influência do ciclo de queima e da temperatura de queima sobre a tensão de ruptura à flexão dos corpos cerâmicos. Verifica-se que as peças queimadas no ciclo de queima lento apresentaram valores de tensão de ruptura superiores. Como discutido anteriormente, este comportamento está relacionado ao maior tempo de exposição dos corpos cerâmicos nas máximas temperaturas de queima quando se utiliza o ciclo de queima tradicional. Isto irá favorecer a cinética das reações bem como permite uma maior aproximação do equilíbrio termodinâmico.

Para ambos os ciclos de queima a tensão de ruptura à flexão aumenta à medida que se aumenta a temperatura de queima. Este comportamento está relacionado a dois fatores: i) primeiramente à formação de fases cristalinas (silicatos e aluminossilicatos de cálcio e/ou magnésio). Tem sido reportado [10] que estas fases possuem elevada resistência mecânica; e ii) a formação de fase líquida de baixa viscosidade que irá preencher progressivamente os poros abertos à medida que se aumenta a temperatura de queima.

De acordo com as especificações da norma técnica Brasileira para revestimento cerâmico [11], os revestimentos

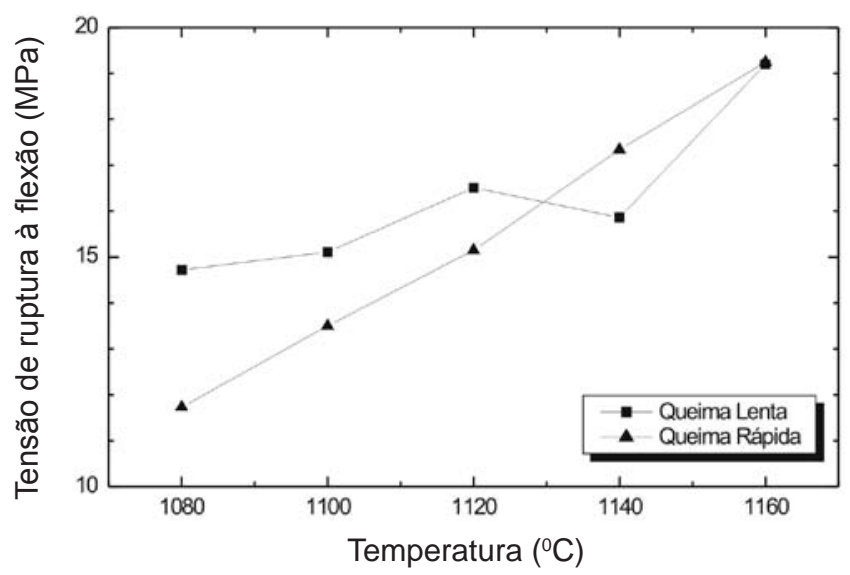

Figura 6: Tensão de ruptura à flexão em função da temperatura de queima.

[Figure 6: Flexural strength as a function of firing temperature.] 
cerâmicos porosos (BIII) devem possuir absorção de água superior a $10 \%$ e tensão de ruptura à flexão igual ou superior a $15 \mathrm{MPa}$, para placas com espessura inferior a 7,5 mm. A especificação de absorção de água foi atingida em toda faixa de temperatura empregada, para ambos os ciclos de queima estudados. Verifica-se também que as peças cerâmicas atingem as especificações brasileiras, em termos da tensão de ruptura à flexão, somente a partir da temperatura de $1100{ }^{\circ} \mathrm{C}$ para o ciclo de queima tradicional, e $1120^{\circ} \mathrm{C}$ para o ciclo de queima rápido. Além disso, os corpos cerâmicos obtidos apresentaram boa estabilidade dimensional com valores de retração linear variando de 1,88 - 2,13\%, para o ciclo de queima tradicional, e 1,96 - 2,18\% para o ciclo de queima rápido. Portanto, foram obtidas melhores propriedades tecnológicas quando se usou um ciclo de queima tradicional de duração de $24 \mathrm{~h}$ frio a frio. No entanto, as diferenças observadas não foram tão significativas em termos de propriedades e menor temperatura. Isto explica a preferência na atualidade do emprego de ciclos de queima rápidos do setor de revestimentos cerâmicos, principalmente relacionadas a ganhos energéticos, produtividade e flexibilidade do processo.

\section{CONCLUSÕES}

Os resultados experimentais deste trabalho indicaram que o emprego de um ciclo de queima tradicional na queima de peças de revestimento poroso (BIII), quando comparado a um ciclo de queima rápido, resultou em melhores propriedades físico-mecânicas, para as condições estudadas.

As peças sinterizadas usando um ciclo de queima tradicional apresentaram menores valores de absorção de água e maiores valores de massa específica aparente e resistência mecânica. O parâmetro de retração linear praticamente não sofreu variação com o ciclo de queima empregado. Os resultados mostraram que um maior tempo de queima, isto é, um maior tempo na temperatura máxima de queima, tende a incrementar a cinética das reações envolvidas. As principais fases cristalinas formadas foram guelenita e anortita, mas pequenas diferenças nas intensidades dos picos de difração evidenciam a influência do ciclo de queima.

\section{AGRADECIMENTOS}

Ao CNPq, CAPES e TECNORTE pelo suporte financeiro.

\section{REFERÊNCIAS}

[1] W. D. Kingery, H. K. Bowen, D. R. Uhlmann, Introduction to Ceramics, $2^{\text {nd }}$ Edition, John Wiley \& Sons, New York, USA (1975) 295.

[2] F. G. Melchiades, E. Quinteiro, A. O. Boschi, Cerâmica Industrial 1, 4-5 (1996) 30.

[3] M. Dondi, M. Marsigli, I. Venturi, Brit. Ceram. Trans. 98, 1 (1999) 12-18.

[4] F. G. Melchiades, E. Quinteiro, A. O. Boschi, Cerâmica Industrial 2, 1-2 (1997) 23.

[5] S. J. G. Sousa, Dissertação de Mestrado, Universidade Estadual do Norte Fluminense, PPGECM-CCT, Campos dos Goytacazes, RJ (2003) 96.

[6] ABNT, NBR MB-305, Determinação da Retração Linear (1984).

[7] ASTM, C 378-88, Test Method for Water Absorption, Bulk Density, Apparent Porosity and Apparent Specific Gravity of Fired Whiteware Products, USA (1988).

[8] ASTM, C 674-77, Flexural Properties of Ceramic Whiteware Materials, USA (1977).

[9] S. Cava, C. A. Paskocimas, E. Longo, Anais do $45^{\circ}$ Cong. Bras. Cerâm., Florianópolis, SC (2001) 265-278.

[10] L. F. B. Marino, A. O. Boschi, Cerâmica Industrial 3, 4-6 (1998) 18-23.

[11]ABNT, NBR 13818, Placas Cerâmicas para Revestimento - Especificações e Métodos de Ensaio (1997).

(Rec. 03/03/2005, Ac. 06/05/2005) 